University of Maryland Francis King Carey School of Law

DigitalCommons@UM Carey Law

4-1-2001

\title{
Consent to the Use of Stored DNA for Genetics Research: A Survey of Attitudes in the Jewish Population
}

\author{
Marc D. Schwartz \\ Karen H. Rothenberg \\ University of Maryland School of Law, krothenberg@law.umaryland.edu \\ Linda Joseph \\ Judith Benkendorf \\ Caryn Lerman
}

Follow this and additional works at: https://digitalcommons.law.umaryland.edu/fac_pubs

Part of the Bioethics and Medical Ethics Commons, Genetics Commons, and the Health Law and Policy Commons

\section{Digital Commons Citation}

Schwartz, Marc D.; Rothenberg, Karen H.; Joseph, Linda; Benkendorf, Judith; and Lerman, Caryn, "Consent to the Use of Stored DNA for Genetics Research: A Survey of Attitudes in the Jewish Population" (2001). Faculty Scholarship. 173.

https://digitalcommons.law.umaryland.edu/fac_pubs/173

This Article is brought to you for free and open access by the Francis King Carey School of Law Faculty at DigitalCommons@UM Carey Law. It has been accepted for inclusion in Faculty Scholarship by an authorized administrator of DigitalCommons@UM Carey Law. For more information, please contact smccarty@law.umaryland.edu. 


\title{
Consent to the Use of Stored DNA for Genetics Research: A Survey of Attitudes in the Jewish Population
}

\author{
Marc D. Schwartz, ${ }^{1 *}$ Karen Rothenberg, ${ }^{2}$ Linda Joseph, ${ }^{2}$ Judith Benkendorf, ${ }^{3}$ and Caryn Lerman ${ }^{1,4}$ \\ ${ }^{1}$ Department of Oncology, Lombardi Cancer Center, Georgetown University Medical Center, Washington DC \\ ${ }^{2}$ University of Maryland School of Law, Baltimore, Maryland \\ ${ }^{3}$ Department of Obstetrics and Gynecology, Georgetown University Medical Center, Washington DC \\ ${ }^{4}$ Department of Medicine, Georgetown University Medical Center, Washington DC
}

The use of anonymized stored tissue is a routine practice in genetic research. Investigators who utilize stored samples are neither required nor able to obtain informed consent before each use. Many genetic studies, however, are conducted on specific ethnic populations (e.g., Ashkenazi Jews). The results in these cases, although individually anonymous, are not anonymous with respect to the ethnicity of the participants. This lack of group anonymity has led to concern about the possibility of stigmatization and discrimination based on the results of the genetic research. In the present study we surveyed Jewish individuals about their attitudes regarding the practice of using stored DNA samples for genetic research. Specifically, we were interested in whether attitudes about informed consent and willingness to participate in genetics research using stored DNA would depend on the circumstances in which the material was collected (i.e., clinical setting vs. research setting) and the characteristics of the disease or trait under investigation. Overall, most respondents reported that written informed consent should be required and that they would be willing to provide such consent. Participants were most willing to provide consent, however, when the sample had been collected in a research rather than clinical setting. Further, participants were more likely to endorse the need for obtain. ing consent when the sample was collected in a clinical setting. Finally, participants

Contract grant sponsor: Hadassah.

*Correspondence to: Marc D. Schwartz, Department of Oncology, Lombardi Cancer Center, 2233 Wisconsin Ave, NW, Suite 317, Washington, DC 20007.

E-mail: Schwartm@georgetown.edu

Received 12 April 2000; Accepted 15 October 2000

Published online 11 January 2001 were significantly less willing to participate in research that examined stereotypical or potentially stigmatizing traits as opposed to research that examined medical or mental illnesses. Am. J. Med. Genet. 00: 000-000, 2001. (C) 2001 Wiley-Liss, Inc.

\section{KEY WORDS: genetic testings; informed} consent

\section{INTRODUCTION}

Scientists' ability to evaluate disease susceptibility has become increasingly refined over the last two decades. In recent years, studies have provided evidence of alterations in some genes that indicate a predisposition to breast cancer (BRCA1 and BRCA2) These studies suggested that alterations in BRCA1 and BRCA2 occurred at a significantly higher rate in Ashkenazi Jewish individuals (i.e., those of Eastern European descent), as compared with the general population [Tonin et al., 1996; Hartge et al., 1999]. Many Jewish individuals sought to participate in studies to confirm those initial findings [Rothenberg, 1997]. This was consistent with the community's successful collaboration with the researchers of Tay-Sachs disease in the 1970s [Kaback et al., 1993; Kaplan, 1998].

After the BRCA1 and BRCA2 reports, another group of investigators found a significantly higher prevalence of a variant in a colorectal cancer susceptibility gene in the Jewish population [Woodage et al., 1998]. When this was reported in the media, however, some leaders of the Jewish community advised Jews to avoid participating in further genetics research [Rothenberg and Rutkin, 1998]. These advisors seemed to fear the discrimination or stigmatization of Jews as a consequence of research identifying the population as being at higher risk for particular diseases [Rothenberg and Rutkin, 1998].

In August of 1999, the National Bioethics Advisory Committee (NBAC) recognized that concerns about stigmatization were not unique to any one ethnic community [NBAC, 1999]. This report, and others

(C) 2001 Wiley-Liss, Inc. 
[King, 1992], underscored the point that genetics research has implications for families and social groups, and that precautions are needed to minimize the social risks to susceptible populations. The NBAC report also urged caution in research involving the use of stored biological materials when samples belong to individuals or groups that are "socially or politically marginalized" [National Bioethics Advisory Commission, 1999]. Other reports have suggested that consultation with these groups in the research development or reporting phases, although not required by current regulations, might help to minimize the social risks [Clayton, 1999]. Likewise, the National Institute of Health"s National Human Genome Research Institute (NIH) has established as a research priority studies of how genetic variation might interact with current concepts of race, ethnicity, and culture [NIH, 1999].

The present report is the first empirical study on the attitudes of Jewish individuals toward genetics research involving the use of stored biological material (DNA). The primary research question was whether attitudes about informed consent and willingness to participate in genetics research using stored DNA would depend upon the circumstances in which the material was collected (i.e., clinical setting vs. research setting) and the characteristics of the disease under investigation. Using hypothetical vignettes we designed a survey to test the hypotheses that rates of willingness to participate would be lower in the clinical vs. the research setting. In addition, we predicted that willingness to participate would be highest for potentially preventable medical diseases (e.g., heart disease), as compared with non preventable diseases (e.g., Huntington disease) and mental illnesses (e.g., schizophrenia). We further expected that willingness to participate would be lowest for behavioral traits (e.g., anxiety), particularly those that might be stigmatizing (e.g., frugality). Sociodemographic and cultural predictors of willingness to consent were also evaluated.

\section{MATERIALS AND METHODS}

\section{Participants}

We recruited a group of Jewish men and women age 18 to 90 years. Introductory letters describing the study were mailed to 1,800 individuals with Jewish surnames. These individuals were identified from a purchased list of individuals with Jewish surnames in the BaltimoreWashington DC Metropolitan area. Of the 1,800 individuals to receive introductory letters, 217 (12\%) no longer resided at the listed address and $200(11 \%)$ were found not to be Jewish. Thus, a total of 1,383 individuals were eligible to participate in the study. Of the 1,383 eligible individuals, $801(58 \%)$ refused to participate in the survey and $308(22 \%)$ could not be reached after 10 attempts. Thus, the final sample consisted of 273 (20\%) Jewish individuals who agreed to complete a telephone survey.

\section{Procedures}

Introductory letters were mailed to each of the 1,800 individuals who were randomly selected from the purchased list. The letters described the study and informed potential participants that they would be contacted via telephone to participate in a survey. A small gift (a telephone message board and marker) was included with the introductory mailing. Two-weeks after the first mailing, potential participants were contacted to complete a telephone survey. The structured survey took about 30 -min to complete and was administered by professional telephone interviewers using a computer-assisted telephone interviewing system.

\section{Description of the Survey}

The survey instrument was designed to evaluate attitudes toward genetics research using stored biological materials. The central characteristic of the survey was the presentation of two hypothetical scenarios. The first scenario described a situation in which the participant had provided an anonymous blood sample as part of a research study to determine how common a specific genetic mutation was in the Jewish population. Later, a group of researchers requests to use his/her blood for another research study on gene alterations found in the Jewish community. The second scenario was identical to the first except that the initial blood sample was provided in a clinical setting (i.e., as part of routine medical care) rather than as part of a research study. In both scenarios, participants were assured that their names could not be linked to the genetic information and that the results could not be released to insurance companies or employers.

After each scenario, participants were presented with 8 hypothetical studies focusing on a gene related to each of the following: 1) a medical illness that can sometimes be prevented or treated if found early (e.g., heart disease); 2) a medical illness that presently cannot be prevented or treated successfully (e.g., Huntington disease); 3) a mental illness (e.g., schizophrenia); 4) alcoholism; 5) frugality; 6) homosexuality; 7) intelligence; and 8) creativity.

\section{Outcome Variables}

Belief in the need for informed consent. For each of the hypothetical studies above, participants were asked to indicate whether they believed that written consent should be required before re-using their DNA We calculated separate summary scores (ranging from 0 to 8 ) for the research and clinical scenarios by summing the total number of affirmative responses for each.

Willingness to provide informed consent. After each scenario, participants were asked whether they would be willing to participate in each of the eight hypothetical studies described above. We calculated separate summary scores (ranging from 0 to 8 ) for the research and clinical scenarios by summing the total number of affirmative responses for each.

\section{Predictor Variables}

Sociodemographics. We assessed the following sociodemographic variables: age, education, gender, marital status. 
Jewish religious identity. Participants were asked "How would you describe your religious identity?". Potential responses were classified as: orthodox, conservative, reform, reconstructionist, secular, atheist/agnostic, don't know.

Jewish cultural identity. Participants were asked to rate the strength of their Jewish cultural identity using the following scale: not at all strong, moderately strong, very strong. In subsequent analyses we divided the sample into those who reported that their Jewish identity was not at all strong/moderately strong $(N=167)$ vs. very strong $(N=106)$.

Concerns regarding anti-Semitism. We assessed concerns about anti-Semitism with the following questions: 1) how concerned are you about antiSemitism in the United States? and 2) how concerned are you about the possibility that genetic information about Jews might contribute to anti-Semitism?. These questions were answered using a three-point Likert scale ranging from 0 (not concerned at all) to 2 (very concerned).

Attitudes toward community consent. We assessed attitudes toward community consent with the following items: 1) in a genetics research study focusing on the Jewish population, how important do you think it is for researchers to consult with members of Jewish religious and community organizations before initiating the study?; 2) how important is it for researchers to get approval of Jewish religious and community organizations before initiating the study?; 3) how important is it for you to be informed about any foreseeable risks to the Jewish community?; 4) how important is it for you to be informed about any foreseeable benefits to the Jewish community?

\section{RESULTS}

\section{Sample Characteristics}

Characteristics of the final sample are displayed in Table I. Participants were equally divided between men and women with a median age of 52. About twothirds of the individuals were married and more than half had greater than a college education. In terms of religious affiliation, all participants were Jewish with about $10 \%$ reporting that they were orthodox, $28 \%$ conservative, $41 \%$ reform or reconstructionist, and $20 \%$ secular, agnostic or atheist. Finally, $39 \%$ of the sample reported that their Jewish cultural identity was very strong.

\section{Beliefs Regarding the Need for Consent}

For both the research and clinical scenarios described in the Methods section, participants were asked whether they believed that researchers should obtain written consent before using stored DNA in eight hypothetical research studies designed to identify genes associated with specific illnesses or traits. Figure 1 shows the proportion of participants who reported that consent should be required for each of the specific tests for each of the two scenarios. For each specific test, the majority of participants $(60-75 \%)$ believed that consent
TABLE I. Sociodemographic Characteristics

\begin{tabular}{lll}
\hline Variable & \multicolumn{1}{c}{ Levels } & $\%$ \\
\hline Age & $<40$ & 23 \\
& $\leq 50$ & 22 \\
Gender & Mate & 55 \\
& Female & 49 \\
Marital Status & Married & 51 \\
Education & Unmarried & 68 \\
& CCollege Graduate & 32 \\
Religious affiliation & College Graduate & 13 \\
& Orthodo Graduate & 36 \\
& Conservative & 10 \\
& Reform/Reconstructionist & 28 \\
& No affiliation (secular/ & 41 \\
& atheist/agnostic) & 20 \\
Jewish cultural identity & Not at all strong & 11 \\
& Moderately Strong & 50 \\
& Very Strong & 39 \\
\hline
\end{tabular}

should be required regardless of whether the DNA was collected in a research or clinical setting.

To compare the research vs. clinical scenario, we created composite measures of belief in the need for consent by summing the total number of affirmative responses for each scenario. Scores on these composites could range from 0 (meaning that the participants did not believe consent should be required for any of the tests) to 8 (meaning that consent should be required for each of the illnesses/traits). We compared the composite consent scores for the research scenario $(M=5.1$, $\mathrm{SD}=3.4)$ to those for the clinical scenario $(M=5.7$, $\mathrm{SD}=3.3$ ) using a paired $t$-test. The results of this analysis demonstrated an increased belief in the need for consent when the samples were collected in a clinical as compared to research setting $(\mathrm{T}(272)=4.0$, $P<0.001$ ). Chi-square comparisons of the individual tests across scenarios revealed that for each of the eight illnesses/traits, participants were more likely to endorse the need for consent in the clinical as compared to the research scenario (see Fig. 1).

\section{Willingness to Participate}

For both the clinical and research scenarios, participants were asked whether they personally would consent to having their stored DNA used in these studies. Figure 2 shows the proportion of participants who reported that they would consent for each of the illnesses/traits across the two scenarios. The willingness to consent to further testing was uniformly high across both the clinical and research scenarios. There was considerable variation, however, in the willingness to consent between preventable/unpreventable disorders and those that might be considered stigmatizing.

To compare willingness to participate across the two scenarios, we created composite measures of participation by summing the affirmative responses in each scenario. The results of a paired $t$-test comparing the research to clinical scenario, indicated that participants were more willing to participate in studies using 


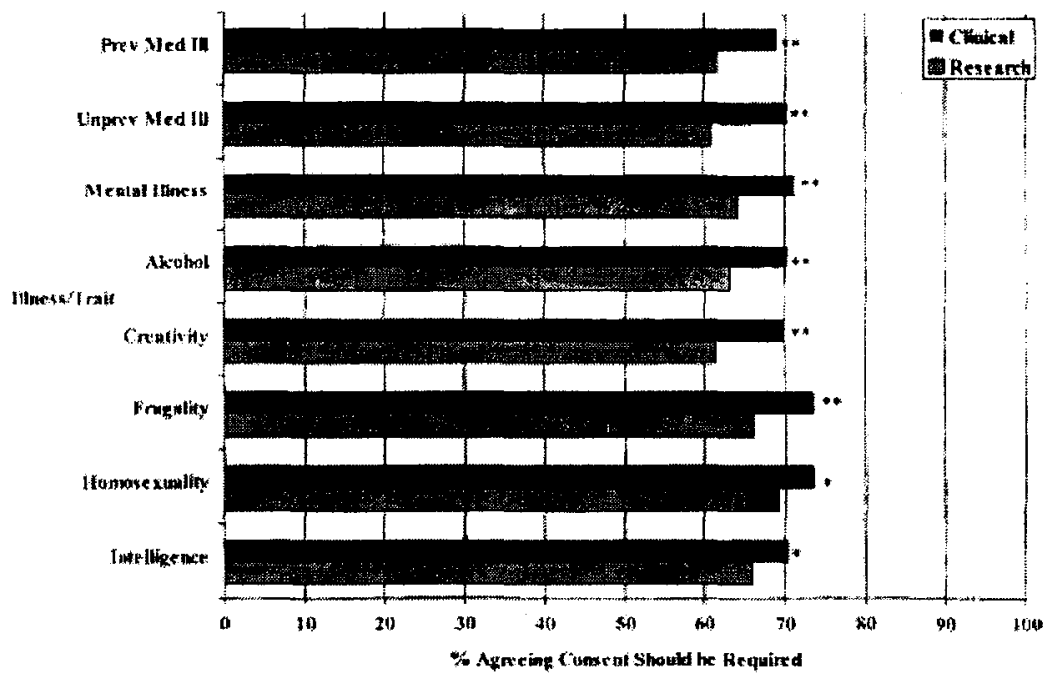

Fig. 1. Should informed consent be required? ${ }^{\circ} P<0.05 ; "{ }^{\prime} P<0.01$.

DNA collected in the research setting $(M=6.4$, $\mathrm{SD}=2.3)$ than the clinical setting $(\mathrm{M}=6.1, \mathrm{SD}=2.7)$ (T $(272)=2.5, P=0.01$ ). Chi-square comparisons across the eight illness/traits revealed that willingness to participate was higher for the research scenario for studies of: untreatable medical illness, treatable medical illness, mental illness, alcoholism, creativity, and intelligence. There was no difference across the two scenarios in willingness to participate in studies of homosexuality and frugality. These two traits had the lowest levels of willingness to participate across the two scenarios (see Fig. 2).

\section{Impact of Study Characteristics on Need for Consent and Willingness to Participate}

To examine whether characteristics of the illness/ traits being studied impacted upon need for consent or willingness to provide consent, we divided the illnesses/ traits into four categories: physical illness (treatable

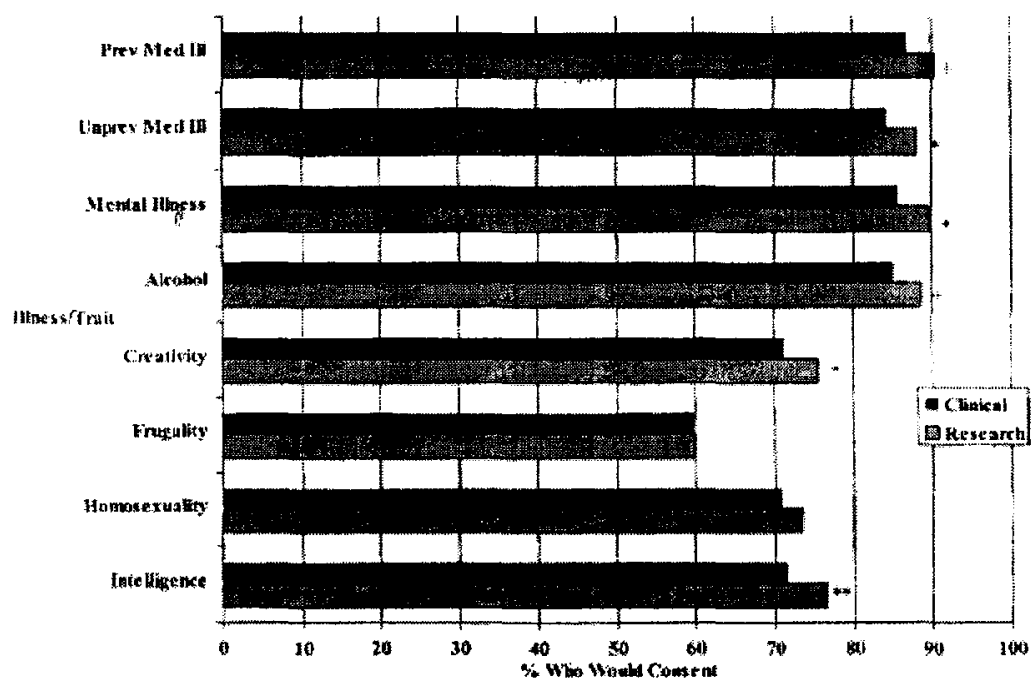

Fig. 2. Would you consent? ${ }^{+} P<0.10 ; " P<0.05 ; "{ }^{*} P<0.01$. 


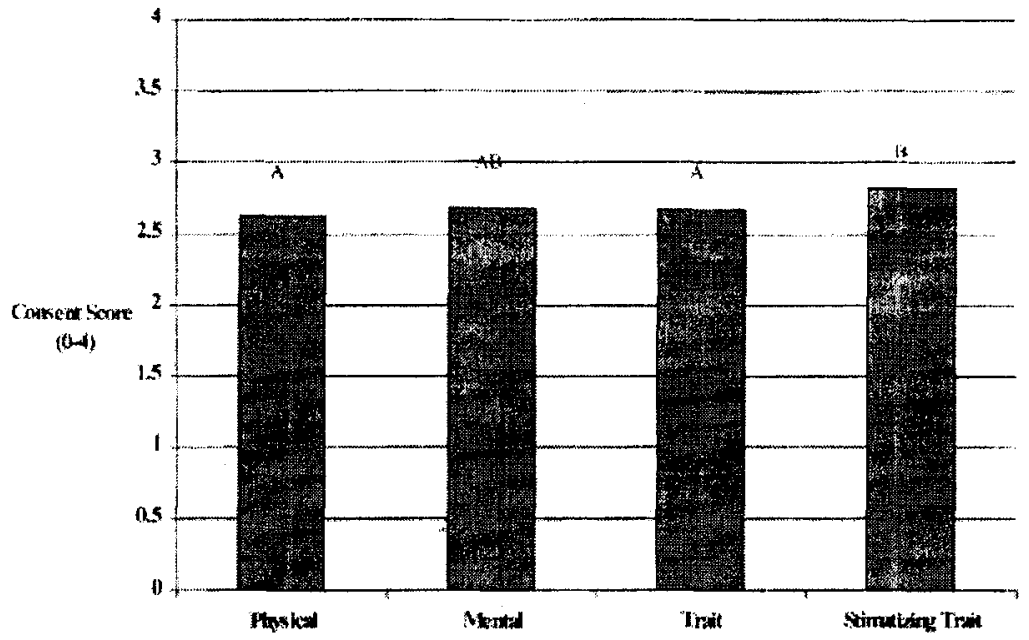

Fig. 3. The impact of test characteristic on belief that consent is required. $F(3,816)(=(5.18 ; P(=\langle 0.0015$. Bars with different letters differ significantly (after Bonferroni correction).

and untreatable physical illness), mental/psychiatric illness (mental illness, alcoholism), traits (intelligence, creativity), and potentially stigmatizing/stereotype confirming traits (frugality, homosexuality). We created composite scores for each grouping by summing the affirmative responses across the two scenarios (see Fig. 3). Repeated measures ANOVA across the four categories revealed significant differences in belief in the need for consent $(F(3,816)=5.2, P=0.002)$. Bonferroni adjusted mean comparisons indicated that participants believed that consent was more important when testing for stigmatizing traits $(\mathrm{M}=2.82, \mathrm{SD}=1.6)$ than when testing for physical illness $(\mathrm{M}=2.61, \mathrm{SD}=1.7)$ or nonstigmatizing traits $(\mathrm{M}=2.67, \mathrm{SD}=1.7)$.

As displayed in Figure 4, analysis using the composite scores on willingness to participate revealed a statistically significant difference in willingness to participate across the four categories $(F(3,816)=70.0$, $P<0.001$ ). Bonferroni corrected mean comparisons revealed that participants were significantly less willing to participate in research designed to identify genes associated with stigmatizing traits $(\mathrm{M}=2.63, \mathrm{SD}=1.61)$

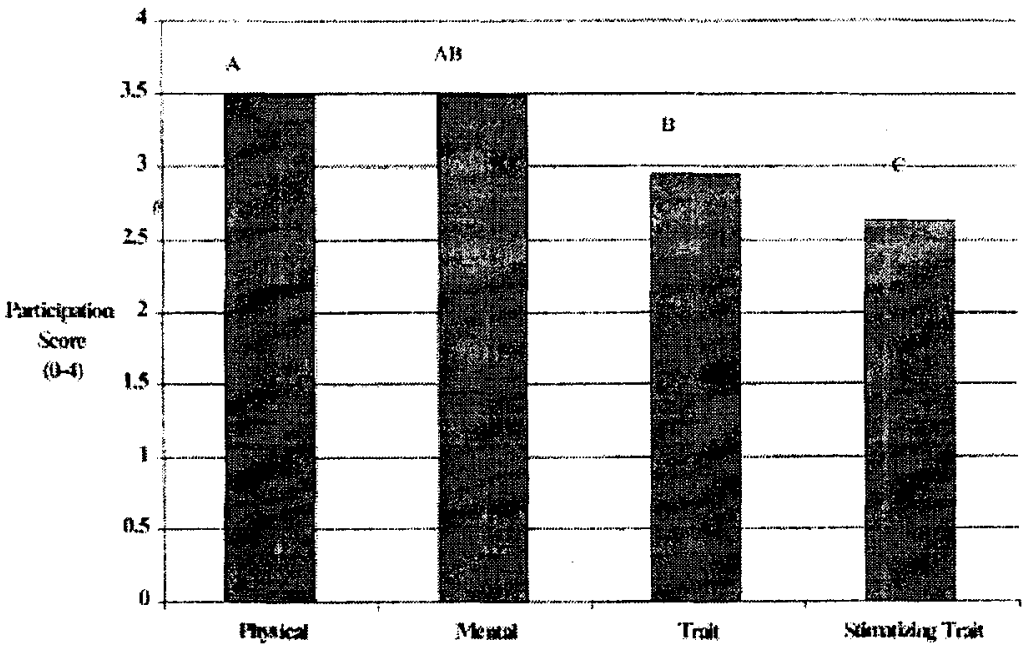

Fig. 4. Impact of test characteristics on willingness to participate. $F(3,816)=69.98 ; P<0.0001$. Bars without common letters differ significantly $\{$ afte Bonferroni correction). 
than research to identify genes associated with medical illness $(M=3.49, \mathrm{SD}=1.1)$, mental illness $(M=3.49$, $\mathrm{SD}=1.1$ ) or non-stigmatizing traits $(\mathrm{M}=2.94, \mathrm{SD}=1.6)$.

\section{Predictors of Consent and Participation}

In exploratory analyses, we examined sociodemographic (age, education level, marital status, sex), attitudinal (concern about anti-Semitism, belief in community consent) and religious (affiliation, Jewish cultural identity) variables as potential predictors of consent and willingness to participate. The variables that predicted consent were age $(r=-0.20, P=0.01)$, education level $(F(2,270)=4.63, P=0.01)$ and belief in community consent $(r=0.13, P=0.04)$. Specifically, individuals who were under 50 , those with college or post-graduate degrees, and those who believed most strongly in the need for community consent, reported the strongest support for informed consent before the use of stored samples (across both scenarios). The only variable that predicted willingness to participate, was Jewish cultural identity $(t(269)=1.94, P=0.05)$. Specifically, individuals with a stronger cultural identity were more willing to participate across scenarios and across illnesses/traits.

\section{DISCUSSION}

This descriptive study is the first to characterize the attitudes of Jews regarding consent for use of stored biological samples in different contexts. Overall, most respondents reported that they believed that written informed consent should be required before reusing stored biological samples for genetics research. This was particularly true when the sample had been acquired for clinical purposes, as compared with a research setting. It is important to point out that we did not assess belief in the need for verbal consent. It is likely that more participants would have endorsed the requirement of verbal consent before reuse of the sample. An even larger proportion of respondents indicated that they would be willing to participate if asked. Again, this was especially true for samples taken in a research setting, as compared with a clinical setting. About $90 \%$ of respondents reported that they would be willing to provide consent for re-use of samples collected in a research setting for studies of mental or physical disorders. Of course the stated willingness of the study subjects to participate in the hypothetical research, does not necessarily indicate that actual participation would be that high. Previous research has demonstrated a relatively poor association between stated intentions and actual behavior [Croyle and Lerman, 1993].

One of the objectives of this study was to test the hypothesis that there would be greater reluctance to provide consent for reuse of samples for conditions that are potentially more stigmatizing. Contrary to expectations, we did not find less willingness to participate in studies of mental illness or behavioral traits. There was a small, but statistically significant, reduction in willingness to participate in studies involving homosexu- ality or frugality, however, both of which are potentially stigmatizing. We also explored participant characteristics that might influence attitudes about consent. Individuals who were younger and had higher levels of education were more likely to believe in the need for consent.

It is important to note that the participants in this study represented a self-selected subset of those ap. proached for the survey (participation rate $=20 \%$ ). This sample was made up of a high proportion of older individuals (more than half were above age 50). Further, this sample had an unusually high level of education (over one half had Masters or Doctoral degrees). It is not surprising that highly educated individuals might be strongly motivated to respond to a survey regarding genetics research. Because education level was positively associated with belief in the need for informed consent, however, it is possible that this survey overestimated concerns about the need for informed consent. Similarly, 39\% of participants in this study reported that their Jewish cultural identity was very strong and $52 \%$ reported a moderately strong Jewish cultural identity. Again, it is not surprising that individuals who strongly identify as Jewish would be particularly interested in participating in a study of attitudes toward genetics research in the Jewish community. Because cultural identity was positively related to willingness to participate in the hypothetical research scenarios, however, this survey may have overestimated the wider Jewish community's willingness to participate in genetics research using stored samples. Clearly, the results of this study must be viewed as representing the attitudes of a subset of the Jewish community, rather than the Jewish community at large or the general population.

In addition to this potential participation bias, a limitation of this study was that we did not provide specific information about the advantages and disadvantages of obtaining additional written consent for re-use of biological specimens. Reports supporting the need for additional consent underscore the importance of individual autonomy in determining specific uses of stored samples, as well as the need to minimize the likelihood of stigmatization or discrimination of particular individuals or groups [Rothenberg and Rutkin, 1998; King, 1992]. The desire of some participants for additional consent, however, must be balanced against the feasibility and costs of re-contacting large numbers of participants, and the likelihood that incomplete capture of previous study participants can result in biased study results. It is not known whether respondents were aware of these issues, or whether providing this information would have influenced their attitudes about re-consent. Another limitation of this study is that we did not provide information about exactly what they had consented to in the original research study. Had the original consent been broad enough to cover experimental studies for a variety of physical illnesses, the need for additional consent may not have been as widely endorsed. Also, because our scenarios asked about consent for a study 
on gene alterations in the Jewish population, it is not known whether the same results would have been obtained for genetics research not specifically targeted toward Jews. It will be important in future studies to learn how attitudes about consent are influenced when additional details about the consent content and process are provided.

Despite these limitations, the present study begins to shed light on attitudes about consent for stored biological samples among individuals in the Jewish community. Although the views of our study respondents may not be representative of this community or the general population at large, these results suggest that some individuals feel strongly that additional written consent should be required for re-use of samples. Further, consent for participation in such studies may depend, in part, on the specific condition to be studied and the context in which the original sample was obtained. Although not sufficient to inform policy at this stage, these findings do raise questions that can be addressed in future studies about the consent content and process. Such studies will be valuable in the development of policy on genetics research targeted at population groups, that may present social implications for race, ethnicity or culture.

\section{ACKNOWLEDGMENTS}

Funding for this survey was provided by Hadassah, The Women's Zionist Organization of America. We gratefully acknowledge the support provided by Patricia Commiskey and Claudia Baquet, of the Center for Health Policy \& Health Services Research at the University of Maryland School of Medicine, for their assistance using Computer Assisted Telephone Interviewing. We also thank Amy Rutkin for her vision and support, and Tamar Lasky and Judith Richter for their assistance.

\section{REFERENCES}

Clayton EW. 1999. Why the use of anonymous samples for rescarch matters. J Law Med Ethics 23:375-377.

Croyle RT, Lerman C. 1993. Interest in genetic testing for colon cancer susceptibility: cognitive and emotional correlates. Prev Med 22:284292.

Hartge P, Struewing JP, Wacholder S, Brody LC, Tucker MA. 1999. The prevalence of common BRCA1 and BRCA2 mutations among Ashkenazi Jews. Am J Hum Genet 64:963-970.

Kaback M, Lim-Steele J, Dabholkar D, Brown D, Levy N, Zeiger K, for the International TSD Data Collection Network. 1993. Tay-Sachs disease-carrier screening prenatal diagnosis and the molecular era. JAMA 270:2306-2315.

Kaplan F. 1998. Tay-Sachs disease carrier scroening: a model for prevention of genetic disease. Genet Test 2:271-292.

King P. 1992. The past as prologue: race, class, and gene discrimination. In Gene mapping: using law and ethics as guides. New York: Oxford University Press.

National Bioethics Advisory Commission. 1999. Research involving human biological materials. In: ethical issues and policy guidance. Volume 1.

National Institutes of Health. 1999. Studies of the ethical legal and social implications of research into human genetic variation. RFA HG-99-002.

Rothenberg KH. 1997. Breast cancer, the genetic "quick fix," and the Jewish community. Ethical, legal, and social challenges Health Matrix 7:97-124.

Rothenberg K, Rutkin AB. 1998. Toward a framework of mutualism: the Jewish community in geneties research. Commun Genet 1:148-153.

Tonin P, Weber B, Offit K, Couch F, Rebbeck TR, Neuhausen S, Godwin AK, Daly M, Wagner-Costalos J, Berman D, Grana G, Fox E, Kane MF, Kolodner RD, Krainer M, Haber DA, Struewing JP, Warner E, Rosen B, Lerman C, Peshkin B, Norton L, Serova O, Foulkes WD, Lynch HT Lenoir GM, Narod S, Garber JE. 1996. Frequency of recurrent BRCAI and BRCA2 mutations in Ashkenazi Jewish breast cancer families. Nat Med 2:1179-1183.

Woodage T, King SM, Wacholder S, Hartge P, Struewing JP, McAdams M. Laken SJ, Tucker MA, Brody LC. 1998. The APCI1307K allel and cancer risk in a community-based study of Ashkenazi Jews. Nat Genet 20:62-65. 